\title{
Humanistiska och samhällsvetenskapliga forskningsperspektiv på ätstörningar, exemplet anorexi $^{1}$
}

\begin{abstract}
ANNA PRESTJAN
Anorexia nervosa och andra ätstörningar diskuteras ständigt $i$ media som ett vanligt och allvarligt problem hos ungdomar och kvinnor. Ätstörningar är ett medicinskt problem, men också ett socialt och kulturellt sådant. Ändå har i Sverige mycket litet forskning bedrivits kring detta ämne ur sociala och kulturella perspektiv. I det följande analyseras det förefintliga forskningsläget inom området samt ges exempel på möjliga problemställningar för fort satt forskning. ${ }^{2}$
\end{abstract}

\section{Forskningsöversikt}

För att få en överblick över den litteratur som ingår i sökresultatet, kan en grov kategorisering av materialet göras utifrån vilket perspektiv eller vilken infallsvinkel forskningen är utförd (specifika teorier redovisas inte.) Uppgiften är inte helt lätt, eftersom de olika perspektiven i viss mån över-

Anna Prestjan, f. 1971, är doktorand i historia vid Örebro universitet. Avhandlingsarbete behandlar dryckenskapen som medicinskt definierat samhällsproblem under senare hälften av 1800-talet. lappar varandra, liksom en och samma text kan sägas tillhöra fler än ett forskningsperspektiv.

1 Denna artikel bygger på en litteraturinventering som utförts inom ramen för ett flerdisciplinärt forskningsprogram kring ätstörningar som startades i samarbete mellan Örebro universitet och Regionssjukhuset i Örebro hösten 1999. Uppgiften var att söka litteratur som behandlar ämnet ätstörningar utifrån ett sociokulturellt perspektiv. Olika sökvägar användes, men utgångspunkten var framför allt databasen Libris och bibliotekskatalogen för The 
Två försök till kategorisering har ändå gjorts. Det första bygger på en sortering av materialet enligt förutbestämda »kodnycklar", som främst talar om hur och på vilken nivå man bedrivit forskningen. De »kodnycklar«som här använts är traditionell medicinhistoria, forskning som bygger på empiriska studier samt teoretiska studier som diskuterar sambandet mellan medicin och kultur utan att göra några empiriska undersökningar. ${ }^{3}$ Men materialet kan även indelas beroende på vilken grundhållning

Wellcome Institute of the History of Medicine i London. Sökningen gjordes först på sökordet ätstörningar (eating disorders), men även på anorexi nervosa och bulimi nervosa. Det visade sig dock att mestadelen av det material som återfanns kring ämnet utifrån de aktuella sökkriterierna handlade om den specifika ätstörningen anorexi nervosa. Anorexi, i sig eller som exempel påätstörningar i allmänhet, är alltså i huvudsak temat i det material som ligger till grund för denna artikel.

2 Litteraturinventeringen begränsades inte bara av de nämnda sökkriterierna utan också av tid och utrymme, därför ska resultatet inte ses som fullständigt utan snarare som en riktlinje och ett underlag för fortsatt arbete. Resultatet omfattar också på grund av språkliga begränsningar endast material påsvenska och engelska. Sökkriterierna medförde vidare en bortrensning av all litteratur med klinisk medicinsk och psykoanalytisk utgångspunkt, liksom mer skönlitterära/ dokumentära s.k. »egenberättelser» och artiklar i dags- och veckopress av typen "jag var anorektiker». Resultatet är ett 60-tal artiklar och ett 20-tal monografier, som på olika sätt utifrån ett sociokulturellt perspektiv vetenskapligt behandlar ämnet ätstörningar/anorexi.

3 Indelningen av materialet utifrån "kodnycklar" är gjord enligt forskningsgruppens önskemål. Själva »kodnycklarna» har omarbetats något av författaren. man i forskningen antar gentemot det undersökta objektet, här anorexi: ett konstruktivistiskt/relativistiskt perspektiv eller ett objektivistiskt/deterministsiskt perspektiv där man från början bestämmer objektets mening. ${ }^{4}$

\section{Den traditionellt medicinhistoriska forskningen}

Den typ av forskning som är lättast att särskilja enligt det första försöket till kategorisering är den traditionellt medicinhistoriska. I Medicinens öga (1990) urskiljer Karin Johannisson fyra grunddrag i vad hon kallar traditionell medicinhistoria. För det första är traditionell medicinhistoria läkarnas och läkarvetenskapens historia. För det andra är den framåtpekande, $\mathrm{d} v \mathrm{v}$ den antar att ny (och senare) kunskap alltid innebär en högre grad av sanning jämfört med tidigare kunskap. För det tredje är traditionell medicinhistoria anakronistisk och utgår från att gårdagens medicinska kunskap kan beskrivas utifrån vår egen tids normer, värderingar och språk. För det fjärde utgår man från att medicinsk kunskap är objektiv i förhållande till det omgivande samhället. Johannisson skiljer den traditionella medicinhistorien från social och kritisk medicinhistoria. Den sociala medicinhistorien belyser medicinen i ett större samhällsperspektiv och sätter patienten, den sjuka människan,

4 En liknande diskussion förs av Tilmann Habermas (1989) „The psychiatric history of Anorexi Nervosa and Bulimi Nervosa: weight concerns and bulimic symptoms in early case reports« $\mathrm{i}$ International Journal of Eating Disorders, vol. 8, nr. 3, s. 259-273. 
i fokus. Detta sätt att skriva medicinhistoria innebär en relativistisk och konstruktivistisk syn på sjukdomsuppfattning och sjukdomsförklaring. Den kritiska medicinhistorien, slutligen, har som sin främsta företrädare Michel Foucault och vill, enligt Johannisson, "skapa medvetenhet om vetenskapens ideologiska beroende och anpassning till samhälleliga ideal.» Samtidigt som den kritiska medicinhistorien är viktig eftersom den sskapar medvetenhet om att medicinen inte rör sig i ett samhälleligt vakuum, utan i ett kraftfält skapat av delvis dolda ideologisystem", är det också en dyster historieskrivning i sina intentioner att "avslöja" medicinens dolda syften, och medikalisering och social kontroll som negativt värdeladdade begrepp är centrala. ${ }^{5}$

I detta sammanhang behöver ensidig, traditionell medicinhistorisk forskning inte vara så negativt laddad som Johannisson antyder, utan ska snarare ses som viktiga bidrag till en mångsidig forskning kring ämnet. Exempel på forskning inom denna kategori är försök att lokalisera tidpunkten för anorexis "upptäckt» inom den medicinska vetenskapen, ${ }^{6}$ ätstörningars/anorexiskarriärsomsjukdom, ${ }^{7}$ samt beskrivningar och analyser av tidiga

5 Johannisson, Karin (1990): Medicinens öga. Sjukdom, medicin och samhälle - medicinska erfarenheter, s. 13-25. Johannisson är kritisk till ett alltför ensidigt användande av det traditionella eller kritiska perspektivet, även om hon medger att dessa båda synsätt också är viktiga.

6 T ex Vandereycken, W. \& van Deth, R. (1989): "Who was the first to describe anorexi nervosa: Gull or Lasègue? « i Psychological Medicine, vol. 19, s. 837-845.

7 TexBeumont,P. J.(1991): »The history of eating and eating disorders" i Clinics in applied nutrition, vol. 1, nr. 2, s. 9-20. fallrapporter. ${ }^{8}$ Inom den traditionellt medicinhistoriska forskningen kring ätstörningar tycks man, med några få undantag, vara överens om att anorexi nervosa som medicinsk enhet "upptäcktes» av fransk eller engelsk medicin på 1870-talet, men att sjukdomsfallen har varit få intill modern tid. Vissa forskare anser emellertid att anorexi enligt dagens kriterier kan spåras ända till 1600och 1700-talet ${ }^{9}$, ja, till och med till medeltida arabisk medicin. ${ }^{10}$

\section{Forskning byggd kring empiriska studier}

En annan typ av forskning är den som bygger på utförda empiriska studier. Vanligen är syftet med dessa undersökningar att fast-

8 T ex Hajal, F. (1982): Psychological treatment of anorexi: a case from the ninth century i Journal of the History of medicine, vol. 37, s. 325-328 samt Silverman, J. (1988): „Anorexi Nervosa in 1888 «i The Lancet, vol. 1, s. 928-930.

9 Joseph Silverman har $\mathrm{t}$ ex i ett antal artiklar hävdat att anorexi dokumenterats både på 1600- och 1700-talet, se t.ex. (1983): „Richard Morton, 1637-1698. Limner of anorexi nervosa: his life and times« i JAMA, vol. 250, nr. 20, s. 2830-2832, (1986): "Anorexi nervosa in seventeenth century England as viewed by physician, philosopher and pedagogue» i International Journal of Eating Disorders, vol. 5, nr. 5, s. 847-853 och (1987): "Robert Whytt, 1714-1765, eighteenth century limner of anorexi nervosa and bulimi« i International Journal of Eating Disorders, vol. 6, nr. 1, s. 143-146.

10 Hajal, Fady (1982): »Psychological treatment of anorexi nervosa: a case from the ninth century" i Journal of the History of Medicine, vol. 37, s. 325-328. 
ställa samband mellan medicinskt iakttagbara symptom och sociokulturella faktorer. Undersökningarna har vanligen ett samtida, men ibland även ett historiskt perspektiv. Ett exempel på dylika studier är Garners och Garfinkels (1980) artikel "Socio-cultural factors in the development of anorexi nervosa", som i en empirisk undersökning jämför attityder till ätande och vikt hos dansstuderande, studerande vid en modellskola, "vanligau kvinnliga studenter, anorexipatienter och musikstuderande. Undersökningen visar att anorexi och viktbekymmer var överrepresenterade hos dans- och modellstuderandena, vilket i sin tur anses bevisa betydelsen av socio-kulturella faktorer som smalt kroppsideal och förväntade prestationer i utvecklingen avätstörningar. ${ }^{11}$ En liknande undersökning utförs av Sharlene Hesse-Biber (1991) i artikeln »Women, weight and eating disorders». Hesse-Biber hävdar att kapitalistiska och patriarkaliska intressen samverkat genom historien i förändringen av kvinnors kroppsuppfattning mot ett allt slankare ideal, och att senare tiders explosionsartade utveckling avätstörningarhoskvinnor harsingrundläggande förklaring idetta. Föratt påvisa samband mellan kulturell press att vara smal och utvecklandet av ätstörningar, genomförde HesseBiber en enkätundersökning bland manliga och kvinnliga collegestudenter. Undersökningen syftade bland annat till att se om de tillfrågades uppfattning om verklig och önskad kroppsvikt överensstämde med en

11 Garner, D. \& Garfinkel, P. (1980): "Socio-cultural factors in the development of anorexi nervosa" i Psychological Medicine, nr. 10, s. 647-656. "kulturellt» eller en "medicinskt» definierad idealvikt. Resultatet visade att kvinnor i högre grad än män följde den »kulturella» idealviktsmodellen, ochatt tendensen bland dessa kvinnor att utveckla ätstörningar var mycket högre än hos kvinnor som följde den "medicinska" idealviktsmodellen. ${ }^{12}$

\section{Icke-empirisk forskning}

Den tredje typen av forskning i denna första tidiga sortering är den som diskuterar sambandet mellan medicinska och sociokulturella faktorer utan att göra några empiriska undersökningar. Denna forskning befinner sig på olika teoretiska nivåer, från meta-teori till teoretiska diskussioner som förankras i den observerbara verkligheten genom t.ex. hänvisning till exempel i form av existerande fall. En diskussion på högre teoretisk nivå förs bl.a. av M. Strober (1986) i »Anorexi Nervosa: History and Psychological Aspects». Strober skiljer i sin framställning själva det fysiska tillståndet, utmärgling till följd av självsvält, från den samhälleliga kontext som symtomen har uppmärksammats inom. Enligt Strober har symtomen inte förändrats, men däremot graden av vetenskapligt intresse och därmed ocksåsätten att närmasig problemet(det vetenskapliga para-

12 Hesse-Biber, Sharlene (1991): „Women, Weight and Eating Disorders. A Socio-Cultural and Political-Economic Analysis« i Women's Studies International Forum, vol. 14, nr. 3, s. 173-191. Hesse-Biber inspireras av Foucaults tankar om maktutövande genom disciplinering av kroppen. Hon ser kvinnors kroppar som kulturella artifakter och som subjekt för kulturellt tvång. 
digmet). Enligt Strober har en utveckling skett från enkla förklaringsmodeller till biopsykosociala tolkningsramar (se nedan). ${ }^{13}$ Även Joan Jacobs Brumberg utgår i sin forskning från att olika sociala och kulturella faktorer i samtiden skapar den form anorexi antar, och att definitionen av anorexi nervosa som sjukdom är resultatet av olika sociala och kulturella processer. Brumberg hävdar vidare att sjukdom måste ses som både en kulturell artifakt och ett somatiskt fenomen. ${ }^{14}$ Ett svenskt exempel är Karin Johannisson (1992), som i artikeln "Kloros (bleksot) - en äldre syster till anorexi?« ställerfrågan om anorexifanns doltbakomandra sjukdomsdiagnoser även före 1870-talet, då sjukdomen av de flesta forskare anses först ha uppträtt på den medicinska arenan. ${ }^{15}$

13 Strober, M. (1986): „Anorexi Nervosa: History and Psycological Concepts" i Handbook of eating disorders. Physiology, Psychology and Treatment of Obesity, Anorexi and Bulimi (eds. Brownell \& Foreyt, New York: Basic Books), s. 231-246. En liknande diskussion förs t.ex. av Stein, D. M. \& Laakso, W. (1988) i „Bulimi: A Historical perspective« i International Journal of Eating Disorders, vol. 7, nr. 2, s. 201-210.

14 Se t.ex. Brumberg, Joan Jacobs (1982):»Chlorotic girls, 1870-1920: a historical perspective on female adolescence» i Child Development, vol. 53, nr. 6, s. 1468-1477, (1986): „Fasting girls»: reflections on writing the history of anorexi nervosa i Monographs of the Society for Research in Child Development, vol. 50, nr. 4-5, s. 93-104 samt (1992): „From psychiatric syndrome to "communicable» disease: the case of anorexi nervosa" i Framing Disease: Studies in Cultural History(ed. Rosenberg/Golden), s. 143-154.

15 Johannisson, Karin (1992): „Kloros (bleksot) en äldre syster till anorexi?» i Läkartidningen, vol. 89, nr. 51-52, s. 4521-4523.
Mycket av den forskning som faller inom denna kategori kan som synes sägas tillhöra vad Karin Johannisson (se ovan) definierat som social eller kritisk medicinhistorisk forskning.

\section{Ett konstruktivistiskt/ relativistiskt forskningsperspektiv}

Man kan alltså även tänka sig en indelning av materialet utifrån vilken grundhållning man intar till undersökningsobjektet - antingen ettkonstruktivistiskt/relativistiskt perspektiv, eller ett perspektiv som mer koncentrerar sig på den medicinska definitionen av ätstörningar och som försöker förstå fenomenet utifrån detta. ${ }^{16}$

Detkonstruktivistiska/relativistiska perspektivet utgår från att utmärgling till följd av självsvält »alltid» har funnits som fysisk verklighet, men att tolkningarna av fenomenet däremot har skiftat med 1) det medicinska paradigmet ( se t.ex. Strober (1986), ovan) och/eller 2) kulturella och sociala mönster. Det är således tolkningarna av fenomenet som är relativa, medan symtomen, utmärgling till följd av självsvält, är absoluta. Enligt detta perspektiv utvidgas anorexibegreppet till att helt enkelt innebära alla typer av självsvält. Medeltidens "heliga» anorektiker med religiösa motiv är alltså jämförbar med dagens viktfixerade anorektiker, eftersom de båda utmärks av självsvälten. Inom detta perspektiv anser man alltså att även motiv och orsaker bakom självsvältsbeteendet genom historien är tid-

16 Se not 2. 
lösa och har varit desamma, men tolkats olika. Man söker hos historiska fall efter kriterier som stämmer överens med dagens. Till detta synsätt sluter sig t.ex. Cajsa Lindholm (1991) i artikeln "Törnekrona - nu eller i evigheten?", som behandlar "allmängiltigau centrala temata i anorexi hos ett medeltida helgon, Katarina av Siena. Lindholm finner i beskrivningen av Katarinas av Siena liv den kamp för ett eget livsrum och den konfliktfyllda relation till framför allt modern, som i dag av många anses orsaka anorexi. Anorektikerns försök att skapa kontroll över sitt eget liv fick, enligt Lindholm, en annan mening i den medeltida kulturen. ${ }^{17}$

Under medeltiden betraktades beteendet som något märkligt, men inte nödvändigtvis negativt, och tolkades som gudomlig närvaro eller beundransvärd asketism. I dag betraktas beteendet som avvikande i mer negativ mening, som uttryck för psykisk avvikelse med uttryck i fysiska, för organismen negativa resultat.

Men man kan, å andra sidan, också tänka sig att olika historiska och samhälleliga sammanhang givit mening åt olika motiv och orsaker. T.ex. fanns i den medeltida starkt religiöst präglade miljön motiv för självsvält som inte har någon relevans i dagens samhälle. I dag finns, å andra sidan, motiv och orsaker grundade i vår kultur och vårt samhälle som troligen inte existerade under medeltiden. Detta resonemang kan, och bör, naturligtivs också överföras på kulturella

17 Lindholm, Cajsa(1991): »Törnekrona-nu eller i evigheten? Helig och nutida anorexi i ett objektrelationsperspektivu i Psykisk hälsa, nr. 4, s. 295-313 skillnader mellan samtida samhällen. T.ex. finns en uppfattning om anorexi nervosa som en västerländsk sjukdom med orsaker i vår västerländska kultur. Denna uppfattning ifrågasätts dock av Sing Lee (1996) i artikeln »Reconsidering the status of anorexi nervosa as a western culture-bond syndrome«. Sing menar att anorexi inte längre kan ses som knutet till den specifikt västerländska kulturen, utan snarare till en universell »modernitetskultur». ${ }^{18}$

\section{Ett objektivistiskt/ deterministiskt forskningsperspektiv}

Till skillnad från ett relativistiskt/ konstruktivistiskt perspektiv på ätstörningar, kan man välja att närma sig problemet genom att koncentrera problematiken kring "primär anorexi" (primary anorexi), vars främsta kännetecken är viktfobi och förvrängd kroppsuppfattning hos den sjuka. Primär anorexi är alltså "a separate clinical entity, recognized as such by the medical establishment and known as anorexi nervosau. ${ }^{19}$ Anorexi är, i denna mening, ett fenomen som inte iakttagits före 1870-talet och utan samband med andra former av självsvält, som visserligen uttryckts i samma fysiska symtom, men där orsaker och motiv bakom

18 Lee, Sing (1996): „Reconsidering the status of anorexi nervosa as a western culture-bound syndrome» i Social Science and Medicine, vol. 42, nr. 1, s. 21-34.

19 Vadereycken, W. \& van Deth, R. (1989): „Who was the first to describe anorexi nervosa: Gull or Lasègue?»i Psychological Medicine, vol. 19, s. 837-845. 
självsvälten varit andra. ${ }^{20}$ Så gott som all traditionellt medicinhistorisk forskning antar denna grundhållning. Förhållningssättet har mött kritik, bl.a. av Sing Lee (1995) som i artikeln "Self-starvation in context" diskuterar primär anorexi som i sig en kulturellt konstruerad version av fenomenet självsvält. Lee hävdar vidare att man genom att på detta sätt skapa "generella" kriterier bortser från fenomenets kulturbundenhet och äventyrar full förståelse av detsamma. ${ }^{21}$

\section{Feministisk forskning kring ätstörningar}

En typ av forskning, som visserligen kan inordnas i ovanstående försök till kategorisering, men som på grund av sin omfattning ändå bör nämnas särskilt, är den feministiska forskningen kring ätstörningar. Denna typ av forskning sätter ätstörningar i samband med kvinnors roll i samhället och kvinnors livssituation. Oftast har man ett samtida, men i vissa fall även ett historiskt perspektiv. Den feministiska forskningen grundar sig i den traditionella synen på ätstörningar som ett problem som framför allt förekommer hos (unga) kvinnor. Inom denna forskningsgren ses ätstörningar som anorexi nervosa som orsakade av kulturella krav och begränsningar. Till exempel fokuseras ofta på det allt smalare kvinnokroppsidealet och de hårda krav som massmedier ställer på unga kvinnor att leva upp till detta ideal. Men inom ett feministiskt perspektiv kan också självsvält/anorexi förstås som unga kvinnors sätt att uttrycka protest eller att tillförskaffa sig fullständig kontroll i en situation som upplevs som frustrerande. Man tänker sig också självsvälten som unga kvinnors sätt att söka undvika att inordna sig i en könsordning som bestäms av sexualiteten genom att förskjuta den fysiska utvecklingen. I Patricia Fallons, Melanie A. Katzmans och Susan C. Wooleys (eds.,1994) antologi Feminist Perspecitves on Eating Disorders behandlas frågan om ätstörningar utifrån ett stort antal feministiska infallsvinklar som t.ex. mode, makt, sexualitet och politik..$^{22}$ Diskuterar ätstörningar ut ett feministiskt perspektiv gör också t.ex. Susan Bordo (1993) i Unbearable Weight Feminism, Western Culture and the Body. ${ }^{23}$ Ett stort antal av de artiklar som utgör underlaget för denna artikel har också ett mer eller mindre uttalat feministiskt perspektiv. Kerstin Shands (1997) diskuterar t.ex. i sin artikel »Hur mycket plats får kvinnor (ä)ta upp?« kvinnors förhållande till mat, kropp och rum. Shands tes är att ätstörningar hos kvinnor grundar sig i en känsla av hotade gränser kombinerat med längtan efter att bryta sig ut ur det avgränsade rum

22 Fallon, Patricia, Katzman, Melanie A. \& Wooley, Susan C. (1994): Feminist Perspectives on Eating Disorders. New York: The Guildford Press.

23 Bordo, Susan (1993): Unbearable Weight. Feminism, Culture and The Body. Berkeley: University of California Press. 
som kvinnokroppen utgör i västerländsk kultur samt längtan efter att själv få sätta gränser för sin kropp. ${ }^{24}$

\section{Olika förklaringar till fenomenet självsvält - kort översikt}

Hur man förklarar anorexi är givetvis avhängigt vilket forskningsperspektiv man ansluter sig till. Ovan berörs delvis i redogörelsen för några skilda perspektiv olika typer av förklaringsmodeller, men här ska ändå göras en mer teorianknuten översikt av de traditionella sätten att tolka anorexi nervosa.

Hesse-Biber (1991) har i inledningen till förut nämnda artikel redogjort för de olika typer av förklaringar till anorexi som förekommer i forskning. Enligt Hesse-Biber kan teorierna kring anorexi/ätstörningar delas in i individualistiska, systemorienterade och sociokulturella. De individualistiska teorierna förklarar ätstörningen utifrån avvikelser i kvinnors psykosexuella utveckling (oral fobi, förträngd sexualitet) eller biologiska faktorer (kemisk obalans orsakar depression, som hos kvinnor är knuten till ätstörningar). De systemorienterade teorierna överlappar i viss mån de individuella, men förlägger problemet till relationer och konflikter mellan människor snarare än inom individen. Dessa teorier antar att ätstörningar som anorexi har sin förklaring i maktkamp mellan barn och förälder, särskilt modern, inom s.k. "anorektiska famil-

24 Shands, Kerstin (1997): „Hur mycket plats får kvinnor (ä)ta upp? Mat, rum och kroppshyddor" i Kvinnovetenskaplig tidskrift, nr. 1, s. 4-11. jer», men lägger liten vikt vid strukturer utanför familjeenheten. De sociokulturella teorierna, till sist, sätter fokus på strukturer i sociala system utanför individen. En i forskningen ofta uppmärksammad sociokulturell faktor är t.ex. den kutlturella pressen på kvinnor att vara smala. ${ }^{25}$

Sammanfattningsvisär förklaringsmodellerna indelade i två grupper: kulturorienterade och individorienterade.

Det verkar dock råda enighet hos de flesta forskare, oavsett vilket perspektiv man intar, om att både kulturella och individuella faktorer har betydelse. Ett exempel på detta är den s.k. biopsykosociala förklaringsmodellen, som ser en interaktion mellan biologiska, psykologiska och sociala faktorer i utvecklandet av ätstörningar som anorexi nervosa. I From Fasting Saints to Anorexic Girls (1994), t.ex., förespråkar författarna Vandereycken och van Deth den biopsykosociala modellen. Vandereycken och van Deth anser, att den biopsykosociala modellen har som självklar följd en individualiserad syn på anorektikern, vilket i sin tur bör leda till avståndstagande från alla försök till enkla och uniforma behandlingsmetoder. ${ }^{26}$

25 Hesse-Biber (1991). s. 173ff. Hesse-Biber gör i sin artikel en sociokulturell och politisk-ekonomisk analys av problemet ätstörningar (se ovan). Hon är kritisk till de tidigare försök till sociokulturella analyser som gjorts, då hon anser att sociokulturella faktorer ofta bara »läggs till» de indiviualistiska teorierna. En mer detaljerad indelning av de individuella förklaringsmodellerna gör t.ex. George Hsu (1983) i artikeln »The aetiology of anorexi nervosa» i Psychological Medicine, nr. 13, s. 231-238.

26 Vandereycken, W. \& van deth, R. (1994): Fromfasting Saints to Anorexic Girls. The History of SelfStarvation, s. 1-4. London: The Athlone Press. 


\section{Tänkbara utgångspunkter för fortsatt forskning kring ämnet}

Bland de exempel påforskningkring anorexi/ ätstörningar som utgör bakgrunden för dennaartikel, finnsnågra exempel påinfallsvinklar som bryter mot de traditionella, och som kan inspirera till fortsatt forskning.

Ett första exempel är Bhanjis, Jolles \& Jolles (1990) artikel "Goethe's Ottilie: an early 19th century description of anorexi nervosa", som exemplifierar hur skönlitteratur skulle kunna användas i historisk forskning kring anorexi, där andra källor fattas. I en analys av beskrivningarna av en av huvudpersonerna i Goethes (1749-1832) roman Die Wahlverwandtschaften från år 1809, den unga Ottilie, spåras flera av de fysiska och psykiska tecken som utmärker anorexi nervosa i modern mening. Författarna drar slutsatsen att skönlitterära texter i egenskap av kulturella artifakter kan bidra med viktig kunskap, inte minst i forskningen kring sociokulturella faktorers betydelse. ${ }^{27}$ Den litteraturinventering som utfördes inför denna artikel visade att det finns ett stort utbud av skönlitterärt material som uttalat handlar om ätstörningar, företrädesvis anorexi. Den moderna skönlitteraturen är dock oftast självbiografisk, och borde därför kunna användas i forskning kring anorexi utifrån ett "underifrånperspektiv«. En jämförelse kunde t.ex. göras mellan individers egna upplevelser av självsvälten och den samhälleliga bilden av fenomenet på olika nivåer.

27 Bhanji, S., Jolles, F. E. F. \& Jolles, R. A. S (1990): "Goethe's Ottilie: an early 19th century description of anorexi nervosu i Journal of the Royal Society of Medicine, vol. 83, s. 581-585.
Skönlitteratur borde alltså kunna användas inte bara som empiriskt källmaterial i syfte att bevisa eller motbevisa olika teorier, utan även som ett "eget« material.

En annan intressant infallsvinkel har Ninni Hjalmers (1998) i debattartikeln "Anorexi-högprioriteradi massmedier, inte i vården". Hjalmers påpekar att massmedierna är mycket intresserade av anorexi och oftast ger en dramatiserad, subjektiv och sensationslysten bild av sjukdomen, medan sjukvården och psykiatrin ofta visar ett $\mathrm{i}$ jämförelse påfallande litet intresse. Följden blir att anorexi »avförvetenskapligas« och att kunskapen om sjukdomen, liksom anorexivården, inte kan utvecklas. ${ }^{28} \mathrm{Hjalmers} \mathrm{inspi-}$ rerar till minst två infallsvinklar. För det första borde det stora material som utgörs av icke-vetenskapliga artiklar i ämnet kunna användas till en studie av massmedias uppmärksammande av problemet över tid. Ökade t.ex. massmedias intresse för saken efter uppmärksammandet av kronprinsessan Victoria anorexi, då bilder av den betydligt avmagrade prinsessan skyltade på varje löpsedel? Förändrades den massmedialt förmedlade bilden av problemet i och med detta? För det andra borde liknande material kunna användas till att belysa dialektiken mellan dels medicinens, dels samhällets i övrigt intresse för företeelsen. Påverkade t.ex. "Victoria-fallet" graden av vetenskapligt intresse för problemet? Och motsvaras nya vetenskapliga rön av massmedial uppmärksamhet?

\footnotetext{
28 Hjalmers, Ninni (1998): „Anorexi - högprioriterad i massmedier; inte i sjukvården« i Läkartidningen, vol. 95, nr. 21, s. 2441-2442.
} 
Ännu ett exempel är Erin O'Connors (1995) artikel "Pictures of Health". O’Connor diskuterar inom ett könsperspektiv uppkomsten av det medicinska fotografiets betydelse för bilden av anorexi. Under 1800-talet började man illustrera kliniska observationer av självsvält hos unga kvinnor med fotografier, något som enligt $\mathrm{O}^{\prime} \mathrm{C}$ Connor gav möjlighet att fastslå sambandet mellan vetenskapligt definierade fysiska behov vad gälldenäringsintag och en estetiskastandard för hur kvinnan borde se ut. ${ }^{29} \mathrm{O}^{\circ}$ Connors artikel inspirerar till nya grepp inom den sociokulturellt betingade forskningen kring ätstörningar, då hon belyser en händelse inom den medicinska diskursen som hon menar fick stor betydelse för synen på kvinnokroppen. Den stora frågan i sammanhanget handlar om medicinens makt $i$ lanserandet av nya uppfattningar om avvikande beteenden i ett samhälle.

Merike Lidholms(1994)artikel „Män och ätstörningar" får utgöra det sista exemplet på forskning som bryter mot den traditionella. Lidholm uppmärksammar det faktum att ätstörningar också finns hos män, även om både anorexi och bulimi traditionellt beskrivs som kvinnosjukdomar. Männen glöms bort, vilket ytterligare förvärrarsituationen för de få som faktiskt drabbas, liksom kunskapen om mäns ätstörningar är eftersatt. ${ }^{30}$ Även om Lidholms artikel framför allt

290 Connor,Erin(1995): „Pictures of Health:Medical Photography and the Emergence of Anorexi Nervosa" i Journal of the History of Sexuality, vol. 5, nr. 4, s. 535-572.

30 Lidholm, Merike (1994): »Män och ätstörningar: När maten blir ett hot" i Psykologtidningen, nr. 20, s. 8-10. är ett referat av den amerikanske professorn Arnold E. Andersens bidrag till den första internationella konferensen på temat män och ätstörningar (Drammen, augusti 1994), så inspirerar den ändå till funderingar kring ätstörningar ur ett manligt könsrollsperspektiv. Att den feministiska forksningen kring ätstörningar är väl utvecklad, har tidigare konstaterats. Men hur skulle man kunna närma sig den manliga sidan av problemet?

\section{Exempel på viktiga framtida forskningsfrågor}

Självsvältär, istortsett, ett problem hos unga människor, och särskilt hos unga kvinnor/ flickor. Kanske kan förklaringar spåras i ett större sammanhang, nämligen i förhållandet mellan barn och mat? Då barn/ ungdomar, mat och relationen dem emellan är de grundläggande beståndsdelarna i fenomenet ätstörningar, är denna infallsvinkel mycket relevant och givande. Denna infallsvinkel har sitt ursprung hos Anna-Karin Larsson, doktorand i historia vid Örebro universitet, somisitt avhandlingsarbetebl.a. tänker behandla förhållandet mellan barn och mat. I det följande diskuteras några fundamentala aspekter på detta förhållande. ${ }^{31}$

För det första är föda livsuppehållande och förhållandet mellan barnet och maten måste regleras med tanke på näringsbehov.

\footnotetext{
31 Observera att diskussionen inte är Anna-Karin Larssons, utan artikelförfattarens, och att AnnaKarin Larsson inte nödvändigtvis i sitt avhandlingsarbete kommer att behandla just dessa frågor.
} 
Mat är nödvändigt. Vi måste ända från födseln äta för att överleva. Men bortsett från det grundläggande tillfredsställandet av de primära behoven, har också näringsintaget utvecklats till ett vetenskapligt område. Mat och ätande har fått en hälsoaspekt och är omgärdat av vetenskapligt rättfärdigade regler kring vad och hur man ska äta för att uppnå önskad fysisk effekt. T.ex. har man i olika tider förespråkat olika typer av diet för att komma till rätta med olika fysiska (eller psykiska) krämpor. Ett central inslag i sekelskiftets alkoholistvård, t.ex., var en kraftig och närande kost, liksom den "höga dieten", bestående av kraftig köttföda, vin och konjak rekommenderades för bl.a. olika typer av matsmältningsproblem. ${ }^{32}$

För det andra ingår förhållandet till mat och ätande som en stor del av uppfostran. Mat och ätandeär omgärdat av sociala regler. Man får inte lämna mat, man får inte vara kräsen, man får inte äta för mycket, man får inte äta alltför ensidigt, man får inte äta annat än på vissa platser och vid vissa tider och man måste uppföra sig på ett särskilt sätt under matintagandet. Argumenten för de olika regler som kringgärdar maten och ätandet hämtas ofta från vetenskapen och näringsläran (ät spenat så du blir stark, ät fisk så du blir intelligent och ät morötter för synens skull), men också från moralen. Till exempel ska man vara tacksam för maten och uppskatta den, vilket dels innebär visad artighet mot den som erbjuder maten, men

32 Se t.ex. P-A Levins (1880) skrift Om spritbegäret och spritförgiftningen., s. 8. Levin ansåg $\mathrm{fö} \mathrm{att}$ den höga dieten var förödande och ofta ledde till alkoholism hos för denna sjukdom disponerade personer. även en ödmjukhet inför medvetenheten om att alla minsann inte får äta sig mätta (tänk på barnen i Afrika!).

Mat kan i uppfostran av barn och unga även användas för att utöva kontroll. I barnböcker utspelas ofta det välkända scenariot då barnet, som inte uppfört sig önskvärt, skickas till sitt rum utan middag. Ett annat vanligt inslag i barnuppfostran är regeln att om man inte äter upp maten, får man ingen efterrätt. Efterrätten används här som belöning för utförande av önskad handling, men det ligger också något lutherskt över det hela; för att njuta måste man ha förtjänat det. Att barn tvingas att smaka av allt och äta upp det som finns på tallriken, kan lika gärna ses som former av maktutövande i allmänhet som sätt att lära barnet vissa matbeteenden; t.ex. att inte vara kräsen. Men barnet kan också vägra äta för att visa sin kontroll över något, nämligen sin egen kropp. En kanske hårddragen jämförelse är vuxna fångar, som både kan förvägras mat och matvägra för att få sina egna krav igenom.

En annan intressant fråga är om barn fostras olika i sin relation till mat och ätande beroende på kön. Att det finns könsskillnader i denna relation när det gäller vuxna människor är uppenbart. Förväntningarna är olika beroende på kön - i allmänhet förväntaskvinnor ha ett mindre intresse för mat än män, medan det är ett tecken på manlighet att äta mycket. Orsakerna till skillnaderna behöver inte enbart ha sin grund i ett smalt kvinnoideal (som är tidsbundet), utan torde i högre grad ha samband med bilden av kvinnan som "moralens väktare (mer tidlöst?). Kvinnor förväntas enligt denna bild vara mer behärskade, mer måttliga och mer återhållsamma när det gäller njutningsme- 
del - så också mat. Om dessa tendenser kan spåras redan $\mathrm{i}$ barnuppfostran, $\mathrm{d} \mathrm{v}$ s om man kan finna tecken på att flickors och pojkars uppfostran vad gäller mat och ätande skiljer sig från varandra, kan man kanske också finna förklaringar till varför det oftast är flickor som utvecklar ätstörningar av typen anorexi nervosa.

Marie Sundberg, universitetsadjunkt i Idrott och hälsa vid Örebro universitet, presenterar i en projektbeskrivning (2000) ytterligare en intressant infallsvinkel..$^{33}$ Sundberg utgår från den ökade fokuseringen på kroppen som skett under de senaste åren. Ett grundantagande är att vi socialiseras till olika synsätt på kroppen beroende på tid, kultur och miljö. En av de viktigaste socialiserande institutionerna i samhället är skolan, menar Sundberg, varför det är av intresse att studera vilka inställningar till kroppen som förmedlats av och i skolan. På undersökningen kan läggas både skolhistoriska, idéhistoriska och kroppskulturella perspektiv.

Sundberghar för avsikt att koncentrerasin undersökning till svenskt 1900-tal. Undersökningsmaterialet skall utgöras av styrdokumenten (läroplaner och kursplaner). Sundbergs studier har hittills visat att det dominerande synsättet på kroppen som förmedlatsavstyrdokumenten varit den instru- mentella synen på kroppen. Detta innebär t.ex. att kroppen ses som en maskin som ska tränas och prestera i vissa syften, ett objekt som vi förväntas arbeta med och förhålla oss till. Sundberg hänvisar i detta sammanhang till Mike Featherstone (1994), som menar att det huvudsakliga budskapet i vår kulturs sätt att se på kroppen är att allt du gör med din kropp måste vara bra för något annat. Vidare urskiljer Sundberg två teman som uttrycker den instrumentella kroppssynen och som kan utgöra analyspunkterna i undersökningen: den nyttiga och hälsosamma kroppen och den presterande kroppen. Marie Sundberg anknyter i sin projektbeskrivning starkt till problemet ätstörningar: de förväntade resultaten av detta „kroppsprojekt» kan vara omöjliga att realisera och en del av förklaringarna tillolika former av kroppsfixeringar kan stå att finna i de synsätt på kroppen som vi så starkt socialiseras till i och av skolan.

Sundbergs undersökning torde vara mycket relevant i forskningen kring ätstörningar. Den välbekanta problematiken kropp-kultur undersöks på ett nytt sätt, med skolan som socialiserande institution i stället för som så ofta t.ex. media. Nya socio-kulturella faktorer som påverkar förekomsten av ätstörningar torde således läggas i dagen eller i varje fall komma under debatt.

33 Följande grundar sig på opublicerade texter av Marie Sundberg, Institutionen för Idrott och hälsa, Örebro universitet (1999/2000). 


\section{Obs att förlagsangivelse saknas på några ställen}

\section{Litteratur}

Beumont, P J (1991): »The history of eating and eating disorders." Clinics in applied nutrition, vol. 1, nr. 2, s. 9-20.

Bhanji, S, Jolles, F E F \& Jolles, R A S (1990): "Goethe's Ottilie: an early 19th century description of anorexia nervosa." Journal of the royal society of medicine, vol. 83, s. 581-585.

Bordo, Susan R. (1993): Unbearable weight: feminism, culture and the body.

Brumberg, Joan Jacobs (1982): „Chlorotic girls, 1870, 1920: a historical perspective on female adolescence." Child development, vol. 53, nr. 6 , . 1468-1477.

Brumberg, Joan Jacobs (1986): „Fasting girls: reflections on writing the history of anorexia nervosa." Monographs of the society for research in child development, vol. 50, nr. 4-5, s. 93-104.

Brumberg, Joan Jacobs (1992): „From psychiatric syndrome to "communicable» disease: the case of anorexia nervosa." Framing disease: studies in cultural history (ed. Rosenberg/Golden), s. 134-154.

Fallon, Katzman, Wooley (eds.) (1994): Feminist perspectives on eating disorders.

Garner, David M \& Garfinkel, Paul E (1980): "Socio-cultural factors in the development of anorexia nervosa." Psychological medicine, nr. 10, s. 647-656.

Habermas, Tilmann (1989): „The psychiatric history of anorexia nervosa and bulimia nervosa: weight concerns and bulimic symptoms in early case reports. "International journal of eating disorders, vol. 8, nr. 3, s. 259-273.

Hajal,Fady (1982): „Psychological treatment of anorexia: a case from the ninth century." Journal of the history of medicine, vol. 37, s. 325-328.

Hesse-Biber, Sharlene (1991): „Women, weight and eating disorders. A socio-cultural and politicaleconomic analysis."Women's studies int. forum, vol. 14, n.r 3, s. 173-191.

Hjalmers, Ninni (1998): „Anorexi - högprioriterad i massmedier, inte i vården." Läkartidningen, vol. 95, nr. 21, s. 2441-2442.

Hsu, George (1983): „The aetiology of anorexia nervosa." Psychological medicine, vol. 13, s. 231-238.

Johannisson, Karin (1990): Medicinens öga. Sjukdom, medicin och samhälle - historiska erfarenheter.

Johannisson, Karin (1992): „Kloros (bleksot) - en äldre syster till anorexi?" Läkartidningen, vol. 89 , nr. 51-52, s. 4521-4523.

Lee, Sing (1995): "Self-starvation in context: towards a culturally sensitive understanding of anorexia nervosa." Social science and medicine, vol. 41, nr. 1, s. 25-36.

Lee, Sing (1996): „Reconsidering the status of anorexia nervosa as a western culture-bound syndrome." Social Science and Medicine, vol. 42, nr. 1, s. 21-34.

Lidholm, Merike (1994): „Män och ätstörningar: När maten blir ett hot." Psykologtidningen, nr. 20, s. 8-10.

Lindholm, Cajsa (1991): »Törnekrona - nu eller i evigheten? Helig och nutida anorexi i ett objektrelationsperspektiv.» Psykisk hälsa, nr. 4, s. 295-313.

O'Connor, Erin (1995): „Pictures of health: medical photography and the emergence of anorexia nervosa." Journal of the history of sexuality, vol. 5, nr. 4, s. 535-572.

Shands, Kerstin W. (1997): »Hur mycket plats får kvinnor (ä)ta upp? Mat, rum och kroppshyddor." Kvinnovetenskapligtidskrift, nr. 1, s. 4-11.

Silverman, Joseph (1983): "Richard Morton, 1637-1698. Limner of anorexia nervosa: his life and times." JAMA, vol. 250, nr. 20, s. 2830-2832.

Silverman, Joseph (1986): "Anorexia nervosa in seventeenth century England as viewed by physician, philosopher and pedagogue." International journal of eating disorders, vol. 5, nr. 5, s. 847-853.

Silverman, Joseph (1987): „Robert Whytt, 1714-1765, eighteenth century limner of anorexia nervosa and bulimia." International journal of eating disorders, vol. 6, nr. 1, s. 143-146.

Silverman, Joseph (1988): "Anorexia nervosa in 
1888." The Lancet, vol. 1, s. 928-930.

Strober, M. (1986): „Anorexia nervosa: history and psychological concepts."

Brownell \& Foreyt (eds.): Handbook of eating disorders. Physiology, Psychology and treatment of obesity, anorexia and bulimia, s. 231-246. New York: Basic Books.
Vandereycken, W. \& van Deth, R. (1989): „Who was the first to describe anorexia nervosa: Gull or Lasègue?" Psychologial medicine, vol. 19, s. 837-845.

Vandereycken, W. \& van Deth, R (1994): From fasting saints to anorexic girls. The history of selfstarvation.

\section{Summary: \\ Sociocultural Perspectives on Eating Disorders, Anorexia Nervosa as an Example}

The article "Sociocultural Perspectives on Eating Disorders, Anorexia Nervosa as an Example» is based on an inventory of literature performed within the frames of a research program around eating disorders. It started as a cooperation between Örebro University and Örebro Medical Centre Hospital. The assignment was to search for literature considering the subject of eating disorders in a sociocultural view. There have been two attempts to categorize the material. The first is a sorting of the material in traditional medical history. This research is built upon empirical studies and theoretical studies discussing the bond between medicine and culture without any empirical research. Secondly, the material can also be divided into groups according to which point of view the researcher has towards the examined object, here Anorexia Nervosa. A constructivistic/relativistic perspective or an objectivistic/deterministic perspective where the meaning of the objective is set from start.

Anorexia Nervosa and other eating disorders are often discussed in media as a serious and common problem among young people, particularly women. Eating disorders are a medical problem, but also a social and a cultural one. In Sweden, very little research on eating disorders has a sociocultural perspective. In this article, the existing field of research is analyzed and examples are given of possible issues for further research.

Summary in English: Lena Lindé 